DOI: 10.4274/ejgg.galenos.2019.29

Eur J Geriatr Gerontol 2019;1(1):17-23

\title{
Relationship Between Frailty and Inflammation
}

\author{
(1) Rana Tuna Doğrul, (1) Hacer Doğan Varan, (1) Muhammet Cemal Kızılarslanoğlu, (1) Mustafa Kemal Kılıç, (1) Güneş Arık, \\ (1) Özgür Kara, (1) Meltem Halil, (1) Mustafa Cankurtaran, (1) Burcu Balam Yavuz
}

Hacettepe University Faculty of Medicine, Department of Internal Medicine, Division of Geriatrics, Ankara, Turkey

\begin{abstract}
Objective: It has been suggested that inflammation plays a role in the pathogenesis of frailty and many studies have been carried out to understand the underlying mechanism. In this study, the relationship between frailty and inflammation was examined.

Materials and Methods: Eight hundred and seventeen patients over 65 years of age were evaluated in this study. Comprehensive geriatric assessment was performed in each patient and the Fried frailty criteria were used to assess physical frailty. Neutrophil count, lymphocyte count, erythrocyte sedimentation rate (ESR), C-reactive protein (CRP), albumin, mean platelet volume and CRP-to-albumin ratio (CAR) and neutrophil-tolymphocyte ratio (NLR) were recorded as inflammatory markers.
\end{abstract}

Results: The median age of the patients was 73 years (minimum-maximum: 65-94). 61.9\% of patients were female ( $n=506)$ and $10.8 \%$ were frail $(\mathrm{n}=88$ ). The median CRP was $0.49 \mathrm{mg} / \mathrm{L}$ (minimum-maximum: $0.10-7.67)$ in frail group $(\mathrm{p}=0.167)$. The CAR was higher in the frail group but there was no significant correlation between high CAR and frailty $(p=0.07)$. The median NLR was 2.17 (minimum-maximum: $0.21-10.17$ ) in the non-frail group and 2.41 (minimum-maximum: 0.62-18.20) in the frail group and the difference between the two groups was significant ( $p=0.014$ ). ESR was significantly higher in the frail group $(p<0.001)$. In multivariate analysis, when models with independently related factors were studied, ESR was found to be significantly related with frailty (OR: $1.026,95 \% \mathrm{Cl}: 1.005-1.047, \mathrm{p}=0.015)$.

Conclusion: Chronic inflammation has been shown to cause frailty directly or indirectly through its destructive effects on the musculoskeletal, respiratory, and hematological systems as well as other physiological intermediate systems. The findings of this study suggest that there may be a relationship between frailty and inflammation.

Keywords: Frailty, inflammation, older adults

\section{Introduction}

The aging of the population brings along health problems. Frailty is a geriatric syndrome defining the physical, functional and cognitive decline that appears as a sequel of particular diseases (e.g., cancer, chronic infection, cardiovascular disease, etc.) but which can also occur in the absence of disease. Frailty is characterized by a high incidence of falls or fractures and increased risk of poor outcomes such as disability, comorbidity, health care expenditures, and premature death $(1,2)$. The frailty notion has gained importance to better understand the health directive of older people and to avoid or at least delay the dependence in late life (3). Fried et al. (1) presented a definition of frailty involving the evaluation of five specific criteria which are weight loss, exhaustion, weak grip strength, slow walking speed, and low physical activity, based on a large data obtained from older individuals.

Although the etiology of frailty is not well known, it has been associated with changes in physiological systems such as brain, immune, endocrine, and skeletal muscle, as well as affecting micronutrients and vitamins in older adults (4). Increased inflammatory markers and cytokines are thought to be major contributors to this process (5). White blood cells (WBCs) and their subpopulation constitute an important part of the inflammation system, and high WBCs counts are associated

Address for Correspondence: Rana Tuna Doğrul MD, Hacettepe University, Faculty of Medicine, Department of Internal Medicine, Division of Geriatrics, Ankara, Turkey

Phone: +90 3123051902 E-mail: rana_tuna@hotmail.com ORCID: orcid.org/0000-0001-9470-5113

Received: Mar 25, 2019 Accepted: May 28, 2019

This article was presented as an oral presentation in 14 ${ }^{\text {th }}$ International Congress of the European Geriatric Medicine Society (EuGMS) in 2018.

Cite this article as: Doğrul RT, Doğan Varan H, Kızılarslanoğlu MC, Kılıç MK, Arık G, Kara Ö, Halil M, Cankurtaran M, Balam Yavuz B. Relationship Between Frailty and Inflammation. Eur J Geriatr Gerontol 2019;1(1):17-23

๑Copyright 2019 by the Academic Geriatrics Society / European Journal of Geriatrics and Gerontology published by Galenos Publishing House. 
with increased disability and mortality risk $(6,7)$. In the Women's Health and Aging Studies, in which a five-year mortality followup was performed, it was shown that increases in neutrophil and decreases in lymphocyte counts were associated with mortality (8). However, the relationship between WBCs and frailty is controversial. While a relationship was found in some of the previous studies, there was no significant relationship in some of the studies. These different results between the studies are based on the small sample size of the studies and the lack of exclusion criteria (9-12).

Chronic inflammatory markers were examined widely in terms of frailty mechanism (13-16). C-reactive protein (CRP), which was found in 1930, is a classical molecule in the circulation of systemic inflammation (17). Studies comparing various inflammatory markers support the role of CRP in frailty etiology $(4,15)$. However, there are also contradictory studies on this subject due to the specific characteristics of the study population $(4,13,15,18)$.

In this study, the relationship between and WBCs count, its subpopulation constitutes, CRP levels were investigated.

\section{Materials and Methods}

\section{Study Population and Procedures}

Eight hundred and seventeen patients who were admitted to our geriatric medicine outpatient clinic were included in this study. The study was designed as a retrospective cohort. Patients over 65 years of age and suitable for the evaluation of frailty status with Fried criteria were included in the study. Participants who met the following criteria were excluded: 1) patients with rheumatic diseases, active infection, malignancy 2) being on corticosteroids for any reason 3) to have received antibiotic treatment up to a month ago. Age, sex, whom living with, education level, chronic diseases, number of drugs, number of falls and history of fracture in the past year, incontinence data were collected. Height $(\mathrm{m})$ and weight $(\mathrm{kg})$ were measured for each participant, body mass index was calculated. Behavioral factors (smoking, alcohol use) were questioned.

The study protocol has been evaluated and approved by the local Ethics Committee. Informed consent was obtained from all the patients or next of kin.

\section{Physical Frailty Definition}

The definition of frailty was established by the Fried frailty criteria, which included the following five elements. 1) Weight: unintentional weight loss of $\geq 5 \%$ in the past year. 2) Weakness: determining the maximal strength of the dominant hand by gender (Three consecutive measurements were taken). Grip strength was determined by using a hand-held dynamometer (Takei A5401). 3) Slowness: determining 15 feet walking time, adjusted for sex and height. 4) Low physical activity: the lowest quintile of International Physical Activity Questionnaire-Short Formscore, which was used to assess weekly energy spending in kcal based on self-reported physical activities. 5) Exhaustion: Fatigue was point out by two questions from the Center for Epidemiologic Studies Depression Scale, including "I felt everything I did was an effort" and "I could not get going". Exhaustion was defined as a positive response to one of these two questions more than 3-4 days per week. The individuals having three or more of these characteristics were considered frail, having one or two characteristics were pre-frail, and without any characteristics were determined as robust (1).

\section{Comprehensive Geriatric Assessment}

Basic activities of daily living (ADL) and instrumental ADL (IADL) were used to evaluate the functional capacity of patients. ADL was evaluated with the Katz Scale which assesses the degree of dependence on six basic activities: feeding, sphincter control, transferring, personal hygiene, dressing, and bathing (19-21). The Lawton Brody scale was used for the evaluation of IADL; this scale assesses eight activities: using a telephone, using transportation, shopping, making meals, doing household chores, taking medications, and managing money (22). Cognition was evaluated clinically and by performing the standardized The Mini-Mental State Examination (MMSE) and The Clock Drawing Test (CDT). The MMSE, developed by Folstein in 1975, is widely used to measure cognitive functions (23). Low scores indicate increased dependence in both tests. Nutritional status of the patients was evaluated by Mini Nutritional Assessment short form and having a total score $\leq 11$ was defined to have a high risk of malnutrition (24). Depressive symptoms were assessed by performing Yesavage Geriatric Depression scale (GDS) short form which total score ranges from zero to fifteen. Scoring six point and above from GDS is interpreted as a symptom of depression (25).

\section{Inflammatory Markers}

White blood cells, lymphocyte, neutrophil counts, mean platelet volume (MPV), albumin levels, CRP and ESR rate of the patients were recorded. C-reactive protein values of two hundred eightyeight patients were achieved. Neutrophil/lymphocyte and CRP/ albumin ratios were calculated.

\section{Statistics}

"Statistical Package for Social Sciences" (SPSS) 22.0 version was used for the statistical analyses. Descriptive statistical analyses were given as frequencies and percentage for categorical variables. Histograms and Kolmogorov-Smirnov tests were used to determine whether the parameters had normal distribution. It was seen that the parameters were not distributed normally and were presented as median (minimum-maximum). Chi-square or 
Fischer exact tests were used for the comparison of categorical variables between groups. The skew distributed continuous variables were analyzed between two groups by Mann-Whitney $\mathrm{U}$ test. The parameters those had significant differences or had $p$ value lower than 0.20 between frail and non-frail patients in univariate analysis were included in Logistic Regression analysis to detect the independently associated parameters for frailty. $\mathrm{P}$ value lower than 0.05 was considered as statistically significant.

\section{Results}

\section{General Characteristics and Comprehensive Geriatric Assessment}

Eight-hundred and seventeen patients aged 65 years and older were included in this study. The median age was 73 years (range 65-94) and 61.9\% ( $n=506)$ were female. 16.3\% $(n=131)$ of the patients were university graduates. Most of them were living with their partners or families (the frequencies were $59.3 \%$ and $25.1 \%$, respectively) and $15.3 \%$ of the participants were living alone. The three most common comorbid conditions were hypertension (69.2\%), diabetes mellitus (35.9\%) and urinary incontinence (35.2\%). 13.3\% $(n=109)$ of the patients were detected to be frail. When the comprehensive geriatric assessment components were evaluated, it was observed that the ADL, IADL, MMSE, CDT, MNA and GDS test scores of the patients in the frail group were significantly worse $(p<0.001)$. Same as, the frail patient group was found to have lower hand grip strength and a slower walking speed of 15 feet $(p<0.001)$. The frequencies of comorbid diseases, geriatric syndromes and comprehensive geriatric assessment are shown in Table 1.

\section{Association Between Inflammatory Markers and Frailty}

When the frail and non-frail groups were compared, albumin levels were significantly lower $(p<0.001), E S R(p<0.001)$ and neutrophil/lymphocyte ratio $(p=0.014)$ were significantly higher in the frail group. There was no significant relationship regarding $\operatorname{CRP}(p=0.167), C R P / a l b u m i n$ ratio $(p=0.07)$ and MPV $(p=0.495)$

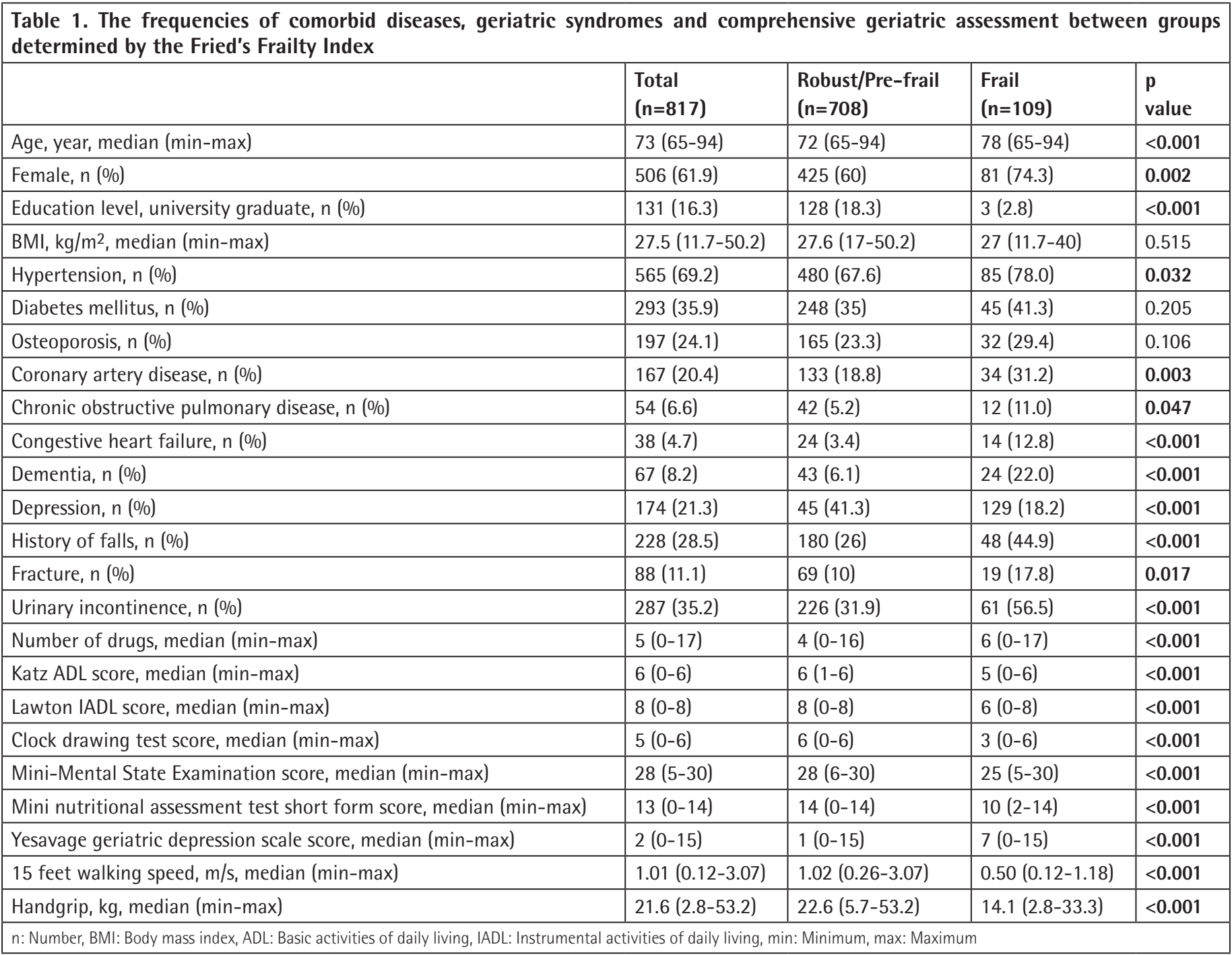


levels. The relationship between frailty and inflammatory markers is shown in Table 2.

In the logistic regression analysis, models were created in order to determine the independently associated factors of frailty. In Model 1, higher ESR was positively associated with greater frailty states (OR: 1.026, 95\% Cl: 1.005-1.047, $\mathrm{p}=0.015$ ). There was no significant difference in neutrophil/lymphocyte ratio (OR: 1.203, 95\% Cl: 0.986-1.468, $\mathrm{p}=0.068$ ) in Model 2. In Model 3, a positive significance was observed in ESR (OR:
1.023, 95\% Cl: 1.002-1.045, $\mathrm{p}=0.031)$. The evaluation of the factors related to frailty by multivariate analysis is shown in Table 3.

\section{Discussion}

This study examined the association of neutrophil count neutrophil/lymphocyte ratio, ESR and CRP levels with frailty. In our study, neutrophil/lymphocyte ratio and ESR, but not CRP, were found to be significantly related to frailty.

\begin{tabular}{|c|c|c|c|c|}
\hline & $\begin{array}{l}\text { Total } \\
(n=817)\end{array}$ & $\begin{array}{l}\text { Robust/Pre-frail } \\
(n=708)\end{array}$ & $\begin{array}{l}\text { Frail } \\
(n=109)\end{array}$ & $\begin{array}{l}p \\
\text { value }\end{array}$ \\
\hline CRP, mg/dL, median (min-max) & $0.43(0.10-7.67)$ & $0.41(0.10-3.19)$ & $0.49(0.1-7.67)$ & 0.167 \\
\hline Leukocyte, $\mathrm{e}^{3} / \mathrm{mL}$, median (min-max) & $7100(3000-14800)$ & $7100(3000-14800)$ & $7400(3100-12600)$ & 0.435 \\
\hline CRP/Albumin, median (min-max) & $0.01(0.0-0.20)$ & $0.01(0.0-0.09)$ & $0.01(0.0-0.2)$ & 0.07 \\
\hline Neutrophil/Lymphocyte, median (min-max) & $2.21(0.21-18.20)$ & $2.17(0.21-10.2)$ & $2.41(0.62-18.2)$ & 0.014 \\
\hline
\end{tabular}

\begin{tabular}{|c|c|c|c|}
\hline & OR & $95 \% \mathrm{Cl}$ & p \\
\hline \multicolumn{4}{|l|}{ Model 1} \\
\hline Age & 1.094 & $1.048-1.141$ & $<0.001$ \\
\hline MMSE score & 0.917 & $0.875-0.960$ & $<0.001$ \\
\hline GDS score & 1.242 & $1.163-1.325$ & $<0.001$ \\
\hline Coronary artery disease & 2.080 & $1.129-3.831$ & 0.019 \\
\hline Sedimentation rate & 1.026 & $1.005-1.047$ & 0.015 \\
\hline Hyperlipidemia & 0.488 & $0.271-0.879$ & 0.017 \\
\hline \multicolumn{4}{|l|}{ Model 2} \\
\hline Age & 1.084 & $1.041-1.128$ & $<0.001$ \\
\hline MMSE score & 0.923 & $0.884-0.964$ & $<0.001$ \\
\hline GDS score & 1.202 & $1.133-1.275$ & $<0.001$ \\
\hline Being a university graduate & 0.231 & $0.054-0.986$ & 0.048 \\
\hline Hyperlipidemia & 0.529 & $0.306-0.915$ & 0.023 \\
\hline Neutrophil/Lymphocyte ratio & 1.203 & $0.986-1.468$ & 0.068 \\
\hline \multicolumn{4}{|l|}{ Model 3} \\
\hline Age & 1.089 & $1.042-1.137$ & $<0.001$ \\
\hline MMSE score & 0.923 & $0.880-0.967$ & 0.001 \\
\hline GDS score & 1.235 & $1.156-1.319$ & $<0.001$ \\
\hline Coronary artery disease & 2.050 & $1.093-3.842$ & 0.025 \\
\hline Being a university graduate & 0.271 & $0.062-1.191$ & 0.084 \\
\hline Hyperlipidemia & 0.505 & $0.278-0.917$ & 0.025 \\
\hline Neutrophil/Lymphocyte ratio & 1.175 & $0.960-1.437$ & 0.118 \\
\hline Sedimentation & 1.023 & $1.002-1.045$ & 0.031 \\
\hline
\end{tabular}


It has been previously demonstrated that aging is associated with high levels of serum inflammatory markers and inflammatory cytokines, and this chronic inflammation is playing an important role in becoming frail $(13,15)$. The interaction between inflammation and frailty could be both direct and indirect. Chronic diseases such as diabetes, chronic kidney disease and ischemic heart disease, with increasing incidence in aging, could lead to chronic inflammation. This inflammation could result in frailty. In contrast, frailty could be associated with chronic inflammation as a result of immobilization and weakness. In addition, CRP gene polymorphism has been shown to change the inflammatory response and increase the risk of developing frailty. Therefore, the combination of these risk factors might contribute to the development of frailty or may lead to an aggravation of frailty $(13,15,26-28)$.

White blood cells and their subpopulations, including neutrophils, lymphocytes, and monocytes, are well known cellular components of the inflammation system. Leng et al. (29) found a significant relationship between the number of neutrophil and monocyte counts with frailty in communitydwelling disabled women. These findings indicate significant risk for frailty even within the normal range of total WBCs counts. Another study investigating the relationship between inflammation and frailty demonstrated that high WBCs counts were associated with increased frailty prevalence in community-dwelling older women, and the next study with the same cohort found that neutrophil and monocyte counts were positively related to frailty. Moreover, in a crosssectional study involving older patients, high neutrophil and low lymphocyte counts were associated with low physical activity, whereas low lymphocyte counts were associated with poor muscle strength (29-31). In our study, while the total WBCs count was not elevated in the frail group, neutrophil/lymphocyte ratio increased significantly. We think that NLR is a better marker for frailty than WBCs, neutrophil and lymphocyte count, as it reflects the combination of two markers.

The relationship between CRP and frailty is not clear. C-reactive protein elevation can be seen in a diversity of other conditions like cancer, cardiovascular diseases, metabolic syndrome, and comorbidity. In some studies, there are no clear disease exclusions as in our study and therefore, as a result of these studies, the relationship between CRP and frailty may be found $(5,32)$. In a study, involving patients with acquired immunity deficiency syndrome, high CRP levels have been associated with skeletal muscle loss (33). Patients were followed-up for nine years in the Cardiovascular Health Study, and CRP independently predicted incident frailty (34). Similarly, elevated levels of CRP were associated with 3-year incident frailty, in the Longitudinal Aging Study of Amsterdam (15). In a recent study procalcitonin, but not IL-6 or CRP, was associated with frailty among older inpatients without infection (35). In our study, there was no significant relationship between CRP and frailty. However, these results were at a borderline value in CRP/albumin ratio. This can be attributed to the low number of patients with CRP. This is a limitation of the study.

The role of inflammation in the development of frailty can be explained by a few mechanisms. The first and major role is mainly based on catabolic effect of pro-inflammatory cytokines on muscles. Studies on this subject have been reported that inflammatory cytokines affect muscle protein synthesis and thus lead to frailty $(36,37)$. The second mechanism is that inflammation may reflect compensatory state in the pathophysiology of frailty (38). The third mechanism is inflammation may be an epiphenomenon, only a marker of causal mechanism $(39,40)$. Excessive and unopposed oxidative stress may be the core mechanism in the development of age-related frailty (41). Oxidative stress with age is sufficient to cause DNA, lipid and muscle damage and this results in cellular and organ dysfunction (42). These findings suggest that inflammation directly or indirectly contributes to the frailty pathophysiology of inflammation.

In our study, age was found to be increasing as the frailty group worsened. Previous studies have supported this relationship between frailty and age $(43,44)$. Physiological changes that occur with aging and the interaction of these changes with pathological mechanisms make aging a predisposing factor for frailty (1). According to the results of our study, as the category of frailty deteriorated, the low level of education increased. Hoogendijk et al. (45) found similar results and emphasized the need to focus on the education level of patients in combating frailty. In our study, we demonstrated that all of the comprehensive geriatric assessment tests were worse in the frail group. In multivariate analyzes, MMSE and GDS have found to be independent related factors with frailty which is in accord with the findings of previous studies (46). With this, the number of comorbid diseases and drug use in the frail group patients is also higher. These results assistance the hypothesis of the "cycle of frailty" which may appear as a result of comorbidities, malnutrition, dementia and depression. Polypharmacy is contemplated to be a risk factor for frailty in the elderly, in which interactions of more than one drug, random drug use and related side effects are likely to aggravate this situation $(47,48)$.

The superior aspects of the study are the involvement of the large number of older patients and the wide exclusion criteria, as presence of malignancy, diagnosis of rheumatologic disease, presence of active infection and removal of patients using steroids for any reason. In addition to healthy individuals living in the community, people with disability 
were also included in the study to generalize study results to the geriatric population.

\section{Study Limitations}

The limitations of the present study were retrospective design and therefore the inability to obtain CRP levels for all patients. In our study, both sexes were evaluated but some studies were evaluated by grouping and significant results were obtained in female gender, there was no significant difference in male sex. Finally, another biomarker, helping to explain the mechanism between frailty and inflammation (e.g., interleukin-6), was not used in the study.

\section{Conclusion}

In our study, there was a significant relationship between frailty and inflammation. Even though the exact relationship has not yet been established, there is increasing evidence that correlates inflammation with frailty in older people. There is a need for multiple strategies for the prevention and treatment of frailty that occurs after the interaction of different system abnormalities.

\section{Ethics}

Ethics Committee Approval: The study protocol has been evaluated and approved by the Hacettepe University Ethics Committee.

Informed Consent: Informed consent was obtained from all the patients or next of kin.

Peer-review: Internally peer-reviewed.

\section{Authorship Contributions}

Surgical and Medical Practices: R.T.D., Concept: R.T.D., M.C.K., B.B.Y., Design: R.T.D., M.C.K., B.B.Y., Data Collection or Processing: R.T.D., H.D.V., M.C.K., M.K.K., G.A., Ö.K., M.H., M.C., B.B.Y., Analysis or Interpretation: R.T.D., M.C.K., B.B.Y., Literature Search: R.T.D., B.B.Y., Writing: R.T.D., M.C.K., B.B.Y.

Conflict of Interest: No conflict of interest was declared by the authors.

Financial Disclosure: The authors declared that this study received no financial support.

\section{References}

1. Fried LP, Tangen $C M$, Walston J, Newman AB, Hirsch C, Gottdiener J, Seeman T, Tracy R, Kop WJ, Burke G, McBurnie MA. Frailty in older adults: evidence for a phenotype. J Gerontol A Biol Sci Med Sci 2001;56:M146-156.

2. Woods NF, LaCroix AZ, Gray SL, Aragaki A, Cochrane BB, Brunner RL, Masaki $K$, Murray $A$, Newman AB. Frailty: emergence and consequences in women aged 65 and older in the Women's Health Initiative Observational Study. J Am Geriatr Soc 2005;53:1321-1330.

3. Wyman JF, Henly SJ. Advancing nursing science through health trajectory research: an introduction. Nurs Res 2011;60(3 Suppl): S1-4.
4. Walston J, McBurnie MA, Newman A, Tracy RP, Kop WJ, Hirsch $\mathrm{CH}_{\text {, }}$ Gottdiener J, Fried LP. Frailty and activation of the inflammation and coagulation systems with and without clinical comorbidities: results from the Cardiovascular Health Study. Arch Intern Med 2002;162:2333-2341.

5. Michaud M, Balardy L, Moulis G, Gaudin C, Peyrot C, Vellas B, Cesari M, Nourhashemi F. Proinflammatory cytokines, aging, and age-related diseases. J Am Med Dir Assoc 2013;14:877-882.

6. Gillum RF, Ingram DD, Makuc DM. White blood cell count, coronary heart disease, and death: the NHANES I Epidemiologic Follow-up Study. Am Heart J 1993;125:855-863.

7. Furlan JC, Vergouwen MD, Fang J, Silver FL. White blood cell count is an independent predictor of outcomes after acute ischaemic stroke. Eur J Neurol 2014;21:215-222.

8. Leng $S$, Xue QL, Huang $Y$, Semba $R$, Chaves $P$, Bandeen-Roche $K$, Fried $\mathrm{L}$, Walston J. Total and differential white blood cell counts and their associations with circulating interleukin-6 levels in community-dwelling older women. J Gerontol A Biol Sci Med Sci 2005;60:195-199.

9. Collerton J, Martin-Ruiz C, Davies K, Hilkens CM, Isaacs J, Kolenda C, Parker C, Dunn M, Catt M, Jagger C, von Zglinicki T, Kirkwood TB. Frailty and the role of inflammation, immunosenescence and cellular ageing in the very old: cross-sectional findings from the Newcastle 85+ Study. Mech Ageing Dev 2012;133:456-466.

10. Gibson KL, Wu YC, Barnett Y, Duggan O, Vaughan R, Kondeatis E, Nilsson BO, Wikby A, Kipling D, Dunn-Walters DK. B-cell diversity decreases in old age and is correlated with poor health status. Aging Cell 2009;8:1825.

11. Semba RD, Margolick JB, Leng S, Walston J, Ricks MO, Fried LP. T cell subsets and mortality in older community-dwelling women. Exp Gerontol 2005;40:81-87.

12. De Fanis U, Wang GC, Fedarko NS, Walston JD, Casolaro V, Leng SX T-lymphocytes expressing CC chemokine receptor-5 are increased in frail older adults. J Am Geriatr Soc 2008;56:904-908.

13. Baylis D, Bartlett DB, Syddall HE, Ntani G, Gale CR, Cooper C, Lord JM, Sayer AA. Immune-endocrine biomarkers as predictors of frailty and mortality: a 10-year longitudinal study in community-dwelling older people. Age (Dordr) 2013;35:963-971.

14. Gale CR, Baylis D, Cooper C, Sayer AA. Inflammatory markers and incident frailty in men and women: the English Longitudinal Study of Ageing. Age (Dordr) 2013;35:2493-2501.

15. Puts MT, Visser M, Twisk JW, Deeg DJ, Lips P. Endocrine and inflammatory markers as predictors of frailty. Clin Endocrinol (Oxf) 2005;63:403-411.

16. Salanitro $A H$, Ritchie $C S$, Hovater $M$, Roth $D L$, Sawyer $P$, Locher $J L$, Bodner E, Brown CJ, Allman RM. Inflammatory Biomarkers as Predictors of Hospitalization and Death in Community-Dwelling Older Adults. Arch Gerontol Geriatr 2012;54:e387-391.

17. Tillett WS, Francis T Jr. Serological Reactions In Pneumonia with A NonProtein Somatic Fraction of Pneumococcus. J Exp Med 1930;52:561-571.

18. Lai HY, Chang HT, Lee YL, Hwang SJ. Association between inflammatory markers and frailty in institutionalized older men. Maturitas 2014;79:329-333.

19. Katz S, Ford Ab, Moskowitz RW, Jackson BA, Jaffe MW. Studies Of IIIness In The Aged. The Index of ADL: A Standardized Measure Of Biological And Psychosocial Function. Jama 1963;185:914-919.

20. Katz S, Downs TD, Cash HR, Grotz RC. Progress in development of the index of ADL. Gerontologist 1970;10:20-30.

21. Arik G, Varan HD, Yavuz BB, Karabulut E, Kara O, Kilic MK, Kizilarslanoglu MC, Sumer F, Kuyumcu ME, Yesil Y, Halil M, Cankurtaran M. Validation of Katz index of independence in activities of daily living in Turkish older adults. Arch Gerontol Geriatr 2015;61:344-350.

22. Graf C. The Lawton instrumental activities of daily living scale. Am J Nurs 2008;18:315-316. 
23. Folstein MF, Folstein SE, McHugh PR, "Mini-mental state". A practical method for grading the cognitive state of patients for the clinician. J Psychiatr Res 1975;12:189-198.

24. Rubenstein LZ, Harker J0, Salvà A, Guigoz $Y$, Vellas B. Screening for undernutrition in geriatric practice: developing the short-form mininutritional assessment (MNA-SF). J Gerontol A Biol Sci Med Sci 2001;56:M366-372

25. Yesavage JA. Geriatric Depression Scale. Psychopharmacol Bull 1988;24:709 711.

26. Brüünsgaard $H$, Pedersen BK. Age-related inflammatory cytokines and disease. Immunol Allergy Clin North Am 2003;23:15-39.

27. Fulop T, Larbi A, Witkowski JM, McElhaney J, Loeb M, Mitnitski A, Pawelec G. Aging, frailty and age-related diseases. Biogerontology 2010;11:547-563.

28. Almeida OP, Norman PE, van Bockxmeer FM, Hankey GJ, Flicker L. CRP $1846 G>A$ polymorphism increases risk of frailty. Maturitas 2012;71:261-266.

29. Leng SX, Xue QL, Tian J, Walston JD, Fried LP. Inflammation and frailty in older women. J Am Geriatr Soc 2007;55:864-871.

30. Leng SX, Xue QL, Tian J, Huang Y, Yeh SH, Fried LP. Associations of neutrophil and monocyte counts with frailty in community-dwelling disabled older women: results from the Women's Health and Aging Studies I. Exp Gerontol 2009;44:511-516.

31. Fernández-Garrido J, Navarro-Martínez R, Buigues-González C, MartínezMartínez M, Ruiz-Ros V, Cauli 0. The value of neutrophil and Iymphocyte count in frail older women. Exp Gerontol 2014;54:35-41.

32. Puzianowska- Kuźnicka M, Owczarz M, Wieczorowska-Tobis K, Nadrowski P, Chudek J, Slusarczyk P, Skalska A, Jonas M, Franek E, Mossakowska M. Interleukin-6 and C-reactive protein, successful aging, and mortality: the PolSenior study. Immun Ageing, 2016;13:21.

33. Kotler DP. Cachexia. Ann Intern Med 2000;133:622-634.

34. Barzilay JI, Blaum C, Moore T, Xue QL, Hirsch CH, Walston JD, Fried LP. Insulin resistance and inflammation as precursors of frailty: the Cardiovascular Health Study. Arch Intern Med 2007;167:635-641.

35. Yang $Y$, Hao Q, Flaherty JH, Cao L, Zhou J, Su L, Shen Y, Dong B. Comparison of procalcitonin, a potentially new inflammatory biomarker of frailty, to interleukin-6 and C-reactive protein among older Chinese hospitalized patients. Aging Clin Exp Res 2018;30:1459-1464.

36. Hubbard RE, O'Mahony MS, Calver BL, Woodhouse KW. Plasma esterases and inflammation in ageing and frailty. Eur J Clin Pharmacol 2008;64:895900 .
37. Toth MJ, Matthews DE, Tracy RP, Previs MJ. Age-related differences in skeletal muscle protein synthesis: relation to markers of immune activation. Am J Physiol Endocrinol Metab 2005;288:E883-891.

38. Hubbard RE, Woodhouse KW. Frailty, inflammation and the elderly. Biogerontology 2010;11:635-641.

39. Serviddio G, Romano AD, Greco A, Rollo T, Bellanti F, Altomare E, Vendemiale G. Frailty syndrome is associated with altered circulating redox balance and increased markers of oxidative stress. Int J Immunopathol Pharmacol 2009;22:819-827.

40. Wu IC, Shiesh SC, Kuo PH, Lin XZ. High oxidative stress is correlated with frailty in elderly chinese. J Am Geriatr Soc 2009;57:1666-1671.

41. Maggio M, Guralnik JM, Longo DL, Ferrucci L. Interleukin-6 in aging and chronic disease: a magnificent pathway. J Gerontol A Biol Sci Med Sci 2006;61:575-584.

42. Ershler WB. A gripping reality: oxidative stress, inflammation, and the pathway to frailty. J Appl Physiol (1985) 2007;103:3-5.

43. Alvarado BE, Zunzunegui MV, Béland F, Bamvita JM. Life course social and health conditions linked to frailty in Latin American older men and women. J Gerontol A Biol Sci Med Sci 2008;63:1399-1406.

44. Sánchez-Garcia S, Sánchez-Arenas R, Garcia-Peña C, Rosas-Carrasco 0 , Avila-Funes JA, Ruiz-Arregui $\mathrm{L}$, Juárez-Cedillo T. Frailty among community-dwelling elderly Mexican people: prevalence and association with sociodemographic characteristics, health state and the use of health services. Geriatr Gerontol Int 2014;14:395-402

45. Hoogendijk EO, van Hout HP, Heymans MW, van der Horst HE, Frijters DH, Broese van Groenou MI, Deeg DJ, Huisman M. Explaining the association between educational level and frailty in older adults: results from a 13year longitudinal study in the Netherlands. Ann Epidemiol 2014;24:538544.e2.

46. Kim S, Park JL, Hwang HS, Kim YP. Correlation between Frailty and Cognitive Function in Non-Demented Community Dwelling Older Koreans. Korean J Fam Med 2014;35:309-320.

47. Gnjidic D, Hilmer SN, Blyth FM, Naganathan V, Cumming RG, Handelsman DJ, McLachlan AJ, Abernethy DR, Banks E, Le Couteur DG. High-risk prescribing and incidence of frailty among older community-dwelling men. Clin Pharmacol Ther 2012;91:521-528.

48. Weiss CO. Frailty and chronic diseases in older adults. Clin Geriatr Med 2011;27:39-52. 